\title{
Comparison of self-perceived weight and desired weight versus actual body mass index among adolescents in Jamaica
}

\author{
Sheila C. Barrett ${ }^{1}$ and Fatma G. Huffman ${ }^{2}$
}

Suggested citation

Barrett SC, Huffman FG. Comparison of self-perceived weight and desired weight versus actual body mass index among adolescents in Jamaica. Rev Panam Salud Publica. 2011;29(4):267-76.

\begin{abstract}
Objective. To compare self-perceived body size, desired body size, and actual body mass index (BMI) among adolescents in Jamaica, and to discuss the implications of these perceptions for chronic disease prevention.

Methods. A total of 276 Jamaican adolescents 14-19 years of age, randomly selected from grades 9-12 at 10 high schools participated in the study, which was conducted in October 2007. The perceived and desired BMI were measured using a silhouette of body figures representing nine BMI categories for males and females; these were compared to participants' actual BMI.

Results. Mean age was $15.6 \pm 1.2$ years. Actual BMI values classified $24.6 \%$ of the participants as underweight; $39.9 \%$ as normal; $14.5 \%$ as overweight; and $21 \%$ as obese. There were significant differences between participants' actual and perceived $B M I(\mathrm{P}<0.01)$, actual and desired BMI $(\mathrm{P}<0.01)$, and perceived and desired BMI $(\mathrm{P}<0.01)$. Gender was significantly different for actual $(\mathrm{P}<0.05)$, perceived, and desired BMI $(\mathrm{P}<0.01)$. Females had significantly higher actual mean BMI than males $(\mathrm{P}<0.05)$. Adolescent males perceived themselves as having a higher BMI and a desired higher BMI than females. There were no differences among ethnicity, age, place of residence, and socioeconomic status on the actual, perceived, and desired BMI in this study population ( $\mathrm{P}>0.05)$.

Conclusions. Females had higher actual BMI and lower perceived BMI than males. Jamaican adolescents, irrespective of ethnicity, age, place of residence, and socioeconomic status, had similar BMI. Interventions are needed to improve knowledge of a healthy body weight and the relationships among body weight, lifestyle choices, and the implications of excess body weight on chronic diseases.
\end{abstract}

Key words Adolescent health; adolescent nutrition; body composition; body mass index; overweight; obesity; Jamaica.
Prevalence of obesity (body mass index [BMI] exceeding the 95th percentile; BMI $>30$ ) among children and adolescents is

\footnotetext{
Florida International University, Miami, Florida, United States of America.

2 Robert Stempel College of Public Health and Social Work, Department of Dietetics and Nutrition, Miami, Florida, United States. Send correspondence to Fatma G. Huffman, huffmanf@fiu.edu
}

increasing worldwide and is a major public health concern (1). It is estimated that, globally, more than 22 million children are overweight (2). Research has shown that obesity among adolescents is an important health issue because diseases, such as type 2 diabetes (T2D), cardiovascular diseases (CVDs), cancer, and sleep apnea, are associated with rising obesity rates (3-5).
While many researchers (1-5) have focused on the implications and health risks associated with the growing obesity problem, others (6-10) have investigated the psychological impact of obesity on self-esteem, self-reported versus actual heights and weights, and associated health risks (11-12). Studies on adolescents' BMI and self-esteem have con- 
sistently found significant effects of BMI on self-esteem and social functioning (9-10). Overweight subjects scored lower on the self-esteem scale (10). Younger, overweight, and obese children were more likely to develop poor self-esteem and poor social attributes than their older, overweight, or obese counterparts. Older adolescents had poorer health in general, but their psychosocial health was not affected by their higher BMI (9).

\section{Perceptions of body image}

Western societies generally emphasize thinness, and obese persons tend to have poorer body image and self-esteem (6). In the United States, body image satisfaction was inversely associated with body weight for female adults (7) and adolescents (6). While there is some evidence that BMI is inversely associated with self-esteem for adolescent populations (10), age may be a moderator with BMI in predicting self-esteem and psychosocial functioning (9).

On the other hand, several studies that compared adolescents' perceived weight and height to their actual measures, reported that adolescents were likely to underestimate their weight (11-12). Underreporting of body weight was found to be more common among female overweight adolescents (13), as well as adolescents with type 2 diabetes (14). Although underestimating weight may serve as a protective factor for selfesteem, inappropriate weight perception may increase the risk of obesity and obesity-related chronic diseases in adolescents.

\section{Perceptions of body image and BMI in Jamaican children and adolescents}

In recent decades, the people of developing countries have been influenced by the lifestyles of industrialized nations. Consequently, developing nations have developed similar rates of overweight, obesity-related morbidity, and mortality (15-16). This trend is plausible in Jamaica, the second largest of the Greater Antilles islands. This is due to its close proximity to the United States. This proximity creates more exposure through travel, trade, and media communication. Research has also linked the increasing obesity rates in Jamaica and other Caribbean countries to high consumption of fatty foods, snacks, soft drinks, and high-energy foods and beverages (17), the same as in the United States. A 2008 report by the Pan American Health Organization representative in Jamaica stated that "up to $52 \%$ of Jamaicans 15-74 years of age are obese by accepted medical standards" (18). Obesity is more prominent among women than men, with more than twothirds of Jamaican women classified as obese. As seen in other countries, obesity is linked to increased risks of chronic-noncommunicable diseases, which account for up to $56 \%$ of deaths in Jamaica (18). Despite the adoption of a Westernized diet and the increased rates of nutrition-related chronic diseases in Jamaica, research is lacking on overweight/obesity of Jamaican adolescents and their weight perceptions.

With the exception of one study (19), studies of overweight and obesity among Jamaican children and adolescents (20-24) did not examine subjects' awareness or knowledge of body weight. The study that did (19), revealed that a higher percentage of males than females knew their own body weight. Both males and females who were overweight and obese felt that their weights were acceptable. Despite the higher BMI among females in that study, more males than females in the overweight category underestimated their weights. Similar results were also found in the obese category; a higher percentage of males compared to females felt that their weight was acceptable (19).

Obesity research in the United States has consistently shown Black girls to be heavier than their White counterparts when matched by age and height (25). It is likely that Jamaican adolescents (most of whom are Black) might be overweight and also might not perceive themselves as overweight. Underestimation of weight has serious implications that can affect health care behaviors of adolescents, many of whom are at risk for developing T2D and CVDs in later years. The purpose of this study was to compare Jamaican adolescents' perceptions of their body weight with their actual BMI. Recognition of actual body weight status is important for designing and implementing lifestyle changes to reduce the onset of chronic diseases associated with obesity.

\section{METHODS AND MATERIALS}

\section{Participants}

A total of 300 Jamaican adolescents 14-19 years of age in grades 9-12 at 10 high schools were selected using a stratified randomized procedure. In order to obtain a representative sample, schools were clustered by parishes and five of the 14 parishes were randomly selected. The five parishes represented both rural and urban locations. Schools were considered urban if they were located in the major metropolitan areas of the selected parishes. The other schools were from non-metropolitan areas and were classified as rural. Schools within each parish were ranked as traditional (schools that focus on academic subjects and typically serve middle- and upper-class families) and nontraditional (schools that concentrated on vocational training and typically serve lower-class families). The purpose was to obtain a representative sample of socioeconomic status (SES). Two schools per parish were selected by "drawing the names from a hat" from each school type; this resulted in a sample of 10 schools. Thirty students per school were randomly selected for a total sample size of 300 .

The random selection of study subjects by grade levels (9-12), school-type (traditional and nontraditional), and place of residence (rural or urban) allowed for inclusion of varying age groups (14-19 years) and a mixture of the different ethnic groups (Blacks and non-Blacks). Blacks represented subjects of African heritage, whereas Non-Blacks included Caucasians, Chinese, Indians, and "mixed-ethnicity." Interracial marriages are common in Jamaica, therefore $7 \%$ of the total population is of mixed ethnicity, which includes combinations of Blacks and Indians, Blacks and Chinese, and Blacks and Caucasians (26).

Of the 300 students who were selected, 276 participated in the study. Of the 24 who did not participate, four had not returned the parental-consent form. Seventeen were absent on the day the data were collected, and three were removed from the data set due to incomplete data. No prescreening for weight was done prior to data collection. Therefore, both normal weight and overweight adolescents were included in the study. Parents were asked to provide written consent, and students whose parents gave written 
consent were asked to sign an assent form. This study was approved by the Institutional Review Board of Florida International University (Miami, Florida, United States), the Division of Standards and Regulations of the Ministry of Health and Environmental Control (Kingston, Jamaica), and the Ministry of Education and Youth (Kingston, Jamaica).

\section{Procedures}

Data were collected by two trained researchers, the principal investigator, and the school nurse. One school per day was targeted. The entire dataset was collected in 3 weeks in October 2007. Questionnaires were administered on data collection day. Subjects completed the silhouettes and demographic questionnaires on their own, and returned them to the researcher on the same day. Each participant's weight was measured using the Professional Medical Beam Balance scale (Health-O-Meter, model 402EXP, Badger Scale Inc., Milwaukee, United States). This scale has a weight capacity of $220 \mathrm{~kg} / 450 \mathrm{lbs}$, with weight graduations of $100 \mathrm{~g} / 4 \mathrm{oz}$, respectively. Subjects were weighed in their clothes, but were asked to remove their shoes. Weight was recorded to the nearest $0.1 \mathrm{~kg}$. The scale was disinfected and recalibrated after each use. Height was taken in centimeters using a stadiometer and recorded to the nearest $0.5 \mathrm{~cm}$.

\section{Measures}

Participants responded to a demographic questionnaire requesting information on gender, age, ethnicity, SES, and place of residence. Actual BMI was calculated based on weight in $\mathrm{kg}$ divided by height in square meters $\left(\mathrm{kg} / \mathrm{m}^{2}\right)$. Subjects were classified as underweight, normal weight, overweight, or obese using the reference standards suggested by Cole and colleagues (27). This method is used internationally and classifies study subjects based on their age and sex (27). The cut-off points for overweight and obesity were established for international use to determine the prevalence of overweight and obesity among children and adolescents $2-18$ years of age. The cut-off points for overweight and obesity by sex and age were defined as "passing through a body mass index of 25 and $30 \mathrm{~kg} / \mathrm{m}^{2}$, which represents adult standard for overweight and obesity" (27). Using this method of classification (27), a 14-year-old male or female could be classified as overweight with a BMI of 22.62 and 23.34, respectively, or obese at a BMI of 27.63 and 28.57, respectively. The internationally accepted cut-off for underweight is a BMI < 18.5. Underweight was further classified as Grades 1-3 where Grade 3 represents BMI $<$ 16; Grade 2: 16 to < 17; and Grade 1: 17 to $<18.5$ (28). This method of classifying underweight represents low BMI for age, which is similar to the standards used for determining underweight in adults (28).

In the present study, each participant was coded as $1=\mathrm{BMI}<16 ; 2=\mathrm{BMI} 16$ to $<17 ; 3=$ BMI 17 to $<18.5 ; 4=$ $\mathrm{BMI} \geq 18.5$ to $<25$ (normal weight); $5=$ BMI > 25 (overweight); and $6=$ $\mathrm{BMI} \geq 30$ (obese) for comparisons of underweight, normal weight, overweight, and obese, respectively. The first three categories were combined to represent underweight when comparing actual, perceived, and desired BMI percentages. The "overweight" subjects in this study included only those whose BMI fell between Cole and colleagues' (27) reference standards for overweight, and below the standards representing obesity for each subject (based on age and sex). Similarly, normal weight referred to subjects with a $\mathrm{BMI}<25$, according to Cole and colleagues' (27) references for age and sex, but did not include those in the underweight categories (28).

\section{Instrument for measuring self- perceived and desired BMI}

In addition to the actual BMI measures, self-perceived and desired BMI were determined. These indices were measured using a scale developed by Bulik and colleagues (29). The scale, designed to determine perceived obesity among adults, is based on self-reported, current body size using standardized figures. Reliability of this scale has been established for actual BMI and selfreported BMI in males $(R=0.90)$ and females ( $R=0.94)$ (29). Prior to the study, the scale was pilot-tested on a group of 37 Jamaican adolescents 14-19 years of age at a high school that was then excluded from the main study. Significant correlations were found between the actual BMI and perceived BMI for males and females $(R=0.45, P<0.05)$ in the pilot study. Actual BMI for males was $24.3 \pm 4.6$ compared to $23.5 \pm 6.4$ for females, whereas perceived BMI was 24.1 \pm 3.2 and $24.1 \pm 6.7$ for males and females, respectively.

Each participant was asked to choose the figure they thought best represented their actual body type, and the body type they wished to have, from among the nine figure types. The nine figure types represented nine levels of BMI values for males (19.8 - 41.5) and females (18.3 - 45.4). The corresponding BMI values obtained from each scale provided the continuous data needed for statistical analyses that compared the perceived and desired BMI with actual BMI values. Additionally, each selected BMI value from the figures was re-coded using Cole and colleagues' classification (27, 28) to determine the proportions of adolescents that were underweight, normal weight, overweight, and obese.

\section{Statistical analyses}

Statistical analyses were performed using SPSS $^{\circledR}$, an IBM company, version 15.0 (SPSS Inc., Chicago, Illinois, United States). Descriptive statistics included percentages, frequencies, means, and standard deviations (SDs). Pearson Correlations were performed among the participants' actual and perceived BMI, actual and desired BMI, and perceived and desired BMI. One-way ANOVAs were used to determine significance of gender, ethnicity, age, place of residence, and SES on actual, perceived, and desired BMI. Results were considered significant if $P<0.05$.

\section{RESULTS}

\section{General characteristics of study participants}

Overall, a higher percentage of females participated. Females also dominated in the 14-16 year age group, ethnicity, place of residence, and school-type. Mean age was $15.6 \pm 1.2$ years. The Levene's Test for Equality of Variance revealed no significant differences for gender based on age, ethnicity, place of residence, schooltype, or weight. However, males were significantly $(P<0.05)$ taller than females (Table 1).

\section{Comparison of actual, perceived, and desired BMI}

Three paired comparisons were performed using Pearson's Correlations: 
TABLE 1. Characteristics of 276 adolescent participants, by gender, in a study on weight perception versus actual body mass index among adolescents in Jamaica, 2007

\begin{tabular}{|c|c|c|c|c|}
\hline & $\begin{array}{c}\text { Male } \\
(n=112)\end{array}$ & $\begin{array}{c}\text { Female } \\
(n=164)\end{array}$ & $\begin{array}{c}\begin{array}{c}\text { Total } \\
(n=276)\end{array} \\
\end{array}$ & \\
\hline Variable & No. (\%) & No. (\%) & No. (\%) & $P$ value $^{\mathrm{a}}$ \\
\hline Age (years) & & & & 0.138 \\
\hline $14-16$ & $80(28.9)$ & $134(48.6)$ & $214(77.5)$ & \\
\hline $17-19$ & $32(11.6)$ & $30(10.7)$ & $62(22.5)$ & \\
\hline Ethnicity & & & & 0.144 \\
\hline Blacks $^{b}$ & $90(32.6)$ & $126(45.6)$ & $216(78.2)$ & \\
\hline Non-Blacks & $22(8.0)$ & $38(13.7)$ & $60(21.8)$ & \\
\hline Place of residence & & & & 0.293 \\
\hline Rural & $63(22.8)$ & 77 (27.8) & $140(49.3)$ & \\
\hline Urban & 49 (17.7) & 87 (31.5) & $136(50.7)$ & \\
\hline School-type & & & & 0.362 \\
\hline Traditionalc $^{c}$ & $52(18.8)$ & $82(29.7)$ & $134(48.6)$ & \\
\hline \multirow[t]{2}{*}{ Non-traditionald } & $60(21.7)$ & $82(29.7)$ & $142(51.4)$ & \\
\hline & Mean $\left(\mathrm{SD}^{\mathrm{e}}\right)$ & Mean (SD) & Mean (SD) & \\
\hline Weight (kg) & $68.63(22.6)$ & $66.32(21.9)$ & 67.27 (22.2) & 0.742 \\
\hline Height $(\mathrm{cm})$ & $173.15(10.4)$ & $164.76(6.9)$ & $168.16(9.4)$ & 0.004 \\
\hline
\end{tabular}

a $P<0.01 . P$ values were calculated for Equality of Variance using Levene's Test. Males were significantly taller than females.

${ }^{\mathrm{b}}$ Non-Blacks $=$ Chinese, Indian, or mixed ethnicity.

c Educating students of higher socioeconomic status, offering mostly academic courses.

${ }^{d}$ Educating students of lower socioeconomic status, offering vocational training.

e Standard deviation.

TABLE 2. Pearson correlations of actual, perceived, and desired body mass index (BMI) among a sample of 276 adolescents in Jamaica, 2007

\begin{tabular}{llll}
\hline \multicolumn{1}{c}{ Variable } & Mean (SD) & $R$ & $\begin{array}{r}P \text { values } \\
(P<0.01)\end{array}$ \\
\hline Actual BMI & $23.80(7.70)$ & $0.61^{\mathrm{b}}$ & 0.01 \\
Perceived BMI & $22.31(2.06)$ & $0.16^{\mathrm{c}}$ & 0.01 \\
Desired BMI & $23.01(4.58)$ & $0.29^{\mathrm{d}}$ & 0.01 \\
\hline a Standard deviation. & & \\
b Significant differences were found between mean BMI for actual and perceived BMI. \\
c Significant differences were found between mean BMl for actual and desired BMl. \\
d Significant differences were found between mean BMl for perceived and desired BMI.
\end{tabular}

(a) actual BMI and perceived BMI; (b) actual and desired BMI; and (c) perceived and desired BMI. Significant associations among actual and perceived BMI $(R=$ $0.61, P<0.01)$, actual and desired BMI $(R=0.16, P<0.01)$, and perceived and desired BMI $(R=0.29, P<0.01)$ were found (Table 2). Follow-up paired sample t-tests $(P<0.05)$ confirmed that underweight subjects $(\mathrm{BMI}<18.5)$ overestimated their body weight, whereas the overweight subjects underestimated.

Figure 1 compares actual, perceived, and desired BMI using Cole and colleagues' classification $(27,28)$ of underweight, normal weight, overweight, and obese. Actual BMI measures indicated that $24.6 \%$ of the sample was underweight, whereas only $2.2 \%$ perceived themselves as underweight, and 6.5\% desired BMI that represents under- weight. A higher percentage of subjects (78.6\%) perceived their weight as normal, but in truth only $39.9 \%$ were classified as normal, based on actual BMI measures. Similarly, a higher percentage of subjects $(18.8 \%)$ perceived their BMI as overweight, but actually $14.5 \%$ were overweight based on the International Obesity Task Force (IOTF) standards (27). In the obese category, fewer obese subjects $(0.4 \%)$ perceived themselves as obese compared to $21 \%$ who were actually obese (Figure 1). When asked what their desired BMI was using the silhouettes, $61.2 \%(n=169)$ of the subjects selected BMI figures that represented normal weight compared to $39.9 \%$ who were actually of normal weight. Interestingly, subjects also selected silhouettes that represented underweight $(n=18$, $6.5 \%)$ and overweight ( $n=59,21.4 \%)$ as their desired BMI. Similarly, $10.8 \%$ $(n=30)$ of subjects desired BMI that classified them as obese.

Figure 2 compares actual, perceived, and desired BMI within the three underweight categories. More than $6 \%$ of study subjects had actual BMI $<16$. Actual BMI classified more subjects as underweight compared to the perceived and desired BMI based on the silhouettes. The silhouettes (intended for adults) did not make finer distinctions to classify subjects as underweight, that is, $\mathrm{BMI}<18.5$. The silhouettes that represented the lowest BMI values for males and females corresponded to a BMI of 19.8 and 18.3, respectively. Actual BMI measures ranged from 12.9 - 50.8. Therefore, actual BMI measures represented all three categories of underweight in contrast to the perceived and desired BMI values that were obtained from the silhouettes. Table 3 compares actual, perceived, and desired BMI by gender using Cole and colleagues' classification of BMI and their sub-classification of underweight. Frequencies, means, and standard deviations for each BMI category are given in Table 3 . There were significant gender differences $(P<0.05)$ for the actual, perceived, and desired BMI by ANOVAs. Females had significantly higher actual BMI than males, whereas males' perceived and desired BMI were higher than females.

In addition to using the silhouettes and measuring actual heights and weights, subjects were asked if they considered their weight to be "below normal," "normal," or "above normal." In all, 5.8\% reported their weight to be below normal compared to actual BMI. Data indicated that $24.6 \%$ of the subjects were underweight. The majority of the subjects $(69.9 \%)$ reported their weight as normal, but only $39.9 \%$ of them had BMI within the normal category. Actual BMI of the subjects revealed that $35.5 \%$ had above normal (overweight and obese) BMI when compared to $19.2 \%$ who perceived their BMI to be above normal.

\section{BMI and demographic characteristics}

Subjects' actual, perceived, and desired BMI were classified as underweight, normal weight, overweight, or obese using international cut-off points based on the variables: gender, ethnicity, age, SES, and place of residence. There were higher percentages of females in all 
FIGURE 1. Comparison of actual, perceived, and desired body mass index (BMI) based on Cole and colleagues' classifications, among a sample of 276 adolescents in Jamaica, 2007

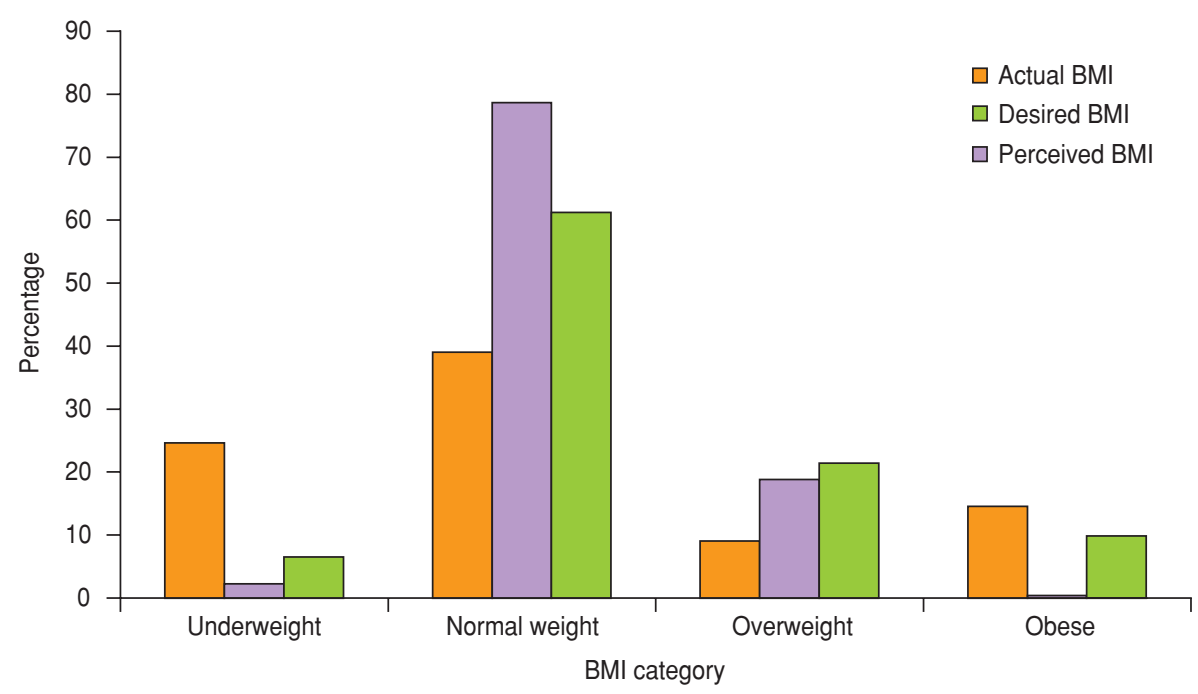

Note: Actual BMI values were classified using Cole and colleagues' $(28,29)$ classification for children 2-18 years based on age and sex. Perceived and desired BMI were determined by converting the scales on the silhouettes to BMI values and were classified using Cole and colleagues' $(28,29)$ classifications.

FIGURE 2. Comparison of categories of thinness based on Cole and colleagues' classifications, among a sample of 276 adolescents in Jamaica, 2007

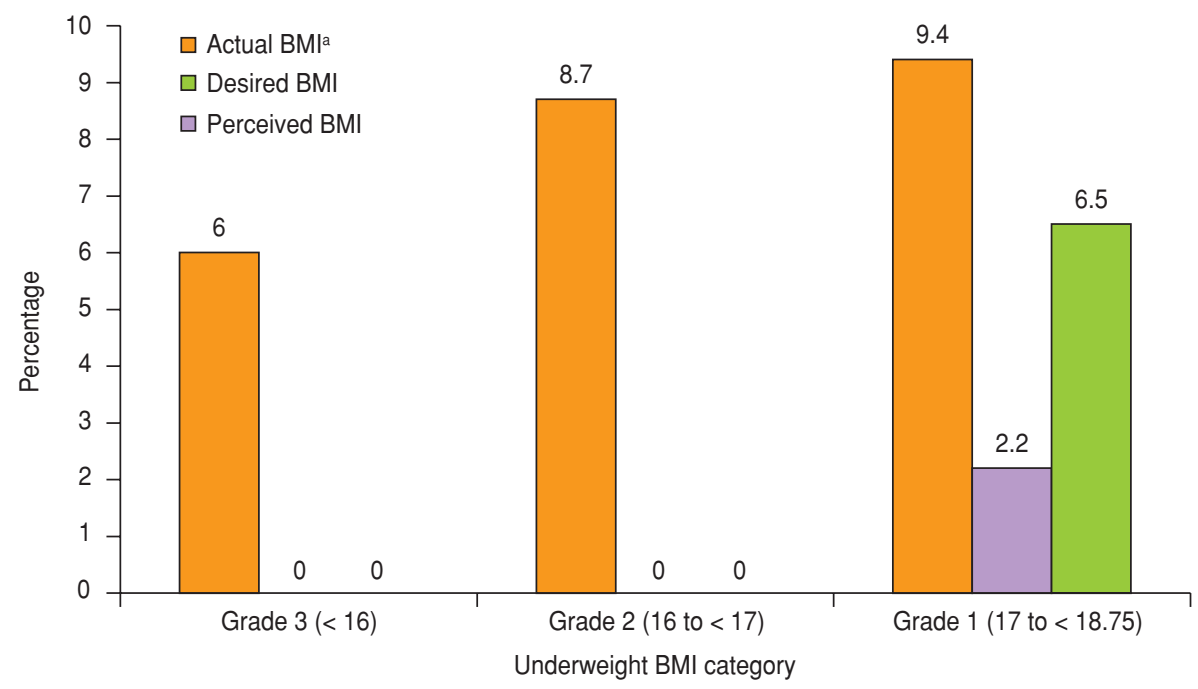

Note: Underweight was classified using Cole and colleagues' (28) classification for thinness.

a $\mathrm{BMI}=$ body mass index.

BMI categories except for the underweight category (Figure 3). The underweight category held a higher percentage $(30.4 \%)$ of males than females (20.7\%) based on actual BMI. Figures 4 and 5 compare perceived and desired BMI by gender. A higher percentage of females perceived themselves to be underweight and normal weight, while males perceived themselves as overweight and desired a larger body frame compared to females.
One-way ANOVAs were used to determine significant differences among actual, perceived, and desired BMI by gender, ethnicity, age, place of residence, and SES (Table 4). Females had significantly higher $(P<0.05)$ actual mean BMI $(24.4 \pm 8.2)$ compared to males $(22.8 \pm$ $6.8)$. Males reported significantly higher $(P<0.01)$ perceived BMI $(23.2 \pm 5.1)$ than females $(22.8 \pm 4.5)$ and also desired higher BMI $(P<0.01)(23.3 \pm 1.87)$ than females $(21.6 \pm 1.9)$. There were no sig- nificant differences among age, SES, ethnicity, and living in rural versus urban locations for all three BMI categories (actual, perceived, and desired).

\section{DISCUSSION}

BMI is considered a crude estimate of body fat since weight includes body fat and muscle tissue. However, BMI as an assessment of obesity in adults has been internationally accepted because it correlates well with body fat $(R=0.7-0.8)$ (30). The present study compared actual BMI using the international cut-off points for age and sex for $2-18$ year olds $(27,28)$. In comparing actual BMI with perceived and desired BMI from the silhouettes, the findings showed significant differences among actual and perceived BMI, actual and desired BMI, and perceived and desired BMI. Males perceived themselves as having significantly higher BMI and also desired significantly higher BMI than females. It is likely that Jamaican male adolescents equate larger body frame with body satisfaction and strength, and do not consider themselves to be overweight. Conversely, adolescent females, who had significantly higher actual BMI than their male counterparts, did not perceive themselves to be overweight. Both males and females did not perceive themselves as overweight; however, the males desired larger frames.

The present findings on gender differences are similar to those of other studies on Jamaican children and adolescents $(20,21,23,24)$, as well as on adults (19, 22). In those studies, Jamaican females were significantly more overweight than males. In the present study, judging from the silhouettes, it seemed that Jamaican adolescent females did not perceive or desire large body frames, although their actual BMI classified some of them as overweight or obese.

This study found a high prevalence of overweight and obesity among the study population, a prevalence that surpasses that of the United States and earlier studies (20-24). Extreme cases of obesity $(\mathrm{BMI}>40)$ were found among the study sample. These subjects were included in the analyses due to the small sample size. This high prevalence of overweight and obesity is of major concern since obesity and adiposity transcend into adulthood, and are strongly associated with incidence of T2D among adults. 
TABLE 3. Comparison of actual, perceived, and desired body mass index (BMI) among a sample of 276 adolescents in Jamaica, by gender, using Cole and colleagues' classification for thinness, overweight, and obese, 2007

\begin{tabular}{|c|c|c|c|c|c|c|}
\hline \multirow[b]{2}{*}{ Gender (BMI categories) } & \multicolumn{2}{|c|}{ Actual BMI } & \multicolumn{2}{|c|}{ Perceived BMI } & \multicolumn{2}{|c|}{ Desired BMI } \\
\hline & No. & Mean (SD) ${ }^{\mathrm{a}}$ & No. & Mean (SD) & No. & Mean (SD) \\
\hline \multicolumn{7}{|l|}{ Males } \\
\hline \multicolumn{7}{|l|}{ Underweight } \\
\hline Grade $3(<16)$ & 10 & $15.01(0.96)$ & 0 & 0 & 0 & 0 \\
\hline Grade $2(16$ to $<17)$ & 9 & $16.83(0.57)$ & 0 & 0 & 0 & 0 \\
\hline Grade $1(17$ to $<18.5)$ & 15 & $17.94(0.42)$ & 0 & 0 & 0 & 0 \\
\hline Overweight $(\geq 25$ to $<30)$ & 14 & $25.80(2.45)$ & 46 & $24.96(1.29)$ & 28 & $25.75(1.70)$ \\
\hline Obese $(\geq 30)$ & 21 & 34.89 (4.32) & 0 & 0 & 15 & $31.10(1.84)$ \\
\hline Missing data & 0 & & 0 & & 3 & \\
\hline Total (males only) & 112 & $22.80(6.80)^{b}$ & 112 & $23.20(5.1)^{b}$ & 112 & $23.3(1.9)^{b}$ \\
\hline \multicolumn{7}{|l|}{ Females } \\
\hline \multicolumn{7}{|l|}{ Underweight } \\
\hline Grade $3(<16)$ & 8 & $15.14(0.72)$ & 0 & 0 & 0 & 0 \\
\hline Grade $2(16$ to $<17)$ & 15 & $16.59(0.32)$ & 0 & 0 & 0 & 0 \\
\hline Normal weight $(\geq 18.5$ to $<25)$ & 67 & $20.84(1.65)$ & 151 & $21.51(1.46)$ & 103 & $20.94(2.58)$ \\
\hline Overweight $(\geq 25$ to $<30)$ & 26 & $26.58(1.38)$ & 6 & $26.20(0.00)$ & 31 & $26.31(0.66)$ \\
\hline Obese $(\geq 30)$ & 37 & $36.64(7.76)$ & 1 & $29.90(0.00)$ & 15 & $32.40(4.16)$ \\
\hline Subtotal (females only) & 164 & $24.20(8.20)^{b}$ & 164 & $22.80(4.50)^{b}$ & 164 & $21.60(1.90)^{b}$ \\
\hline \multicolumn{7}{|l|}{ Subtotal (both males and females) } \\
\hline Grade $3(<16)$ & 18 & $15.07(0.84)$ & 0 & 0 & 0 & 0 \\
\hline Grade $2(16$ to $<17)$ & 24 & $16.68(0.44)$ & 0 & 0 & 0 & 0 \\
\hline Grade $1(17$ to $<18.5)$ & 26 & $17.91(0.42)$ & 6 & $18.30(0.00)$ & 18 & $18.29(0.04)$ \\
\hline Normal weight $(\geq 18.5$ to $<25)$ & 110 & $20.74(1.59)$ & 217 & $21.71(1.44)$ & 169 & $21.34(2.19)$ \\
\hline Overweight $(\geq 25$ to $<30)$ & 40 & $26.31(1.84)$ & 52 & $25.10(1.27)$ & 59 & $26.05(1.28)$ \\
\hline Obese $(\geq 30)$ & 58 & $36.00(6.73)$ & 1 & $29.90(0.00)$ & 30 & $31.82(3.35)$ \\
\hline Missing data & 0 & 0 & 0 & 0 & 3 & 0 \\
\hline Total & 276 & $23.80(7.70)^{b}$ & 276 & $22.31(2.06)^{b}$ & 276 & $23.01(4.58)^{b}$ \\
\hline
\end{tabular}

Source: references 27 and 28.

a Standard deviation.

b $P<0.05$.

FIGURE 3. Comparison of actual body mass index (BMI) by gender among a sample of 276 adolescents in Jamaica, 2007

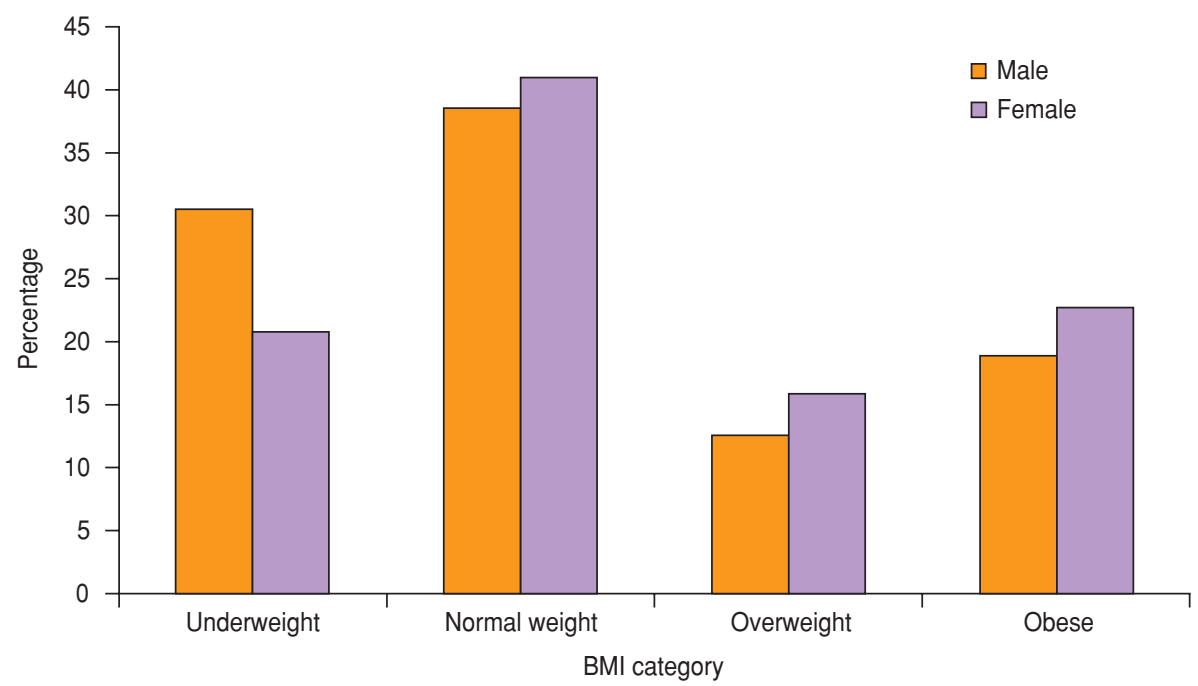

Note: BMI based on actual measures of weights and heights and classified using Cole and colleagues' $(27,28)$ classification of BMl for children 2-18 years based on age and sex. Higher percentages of females were found in all BMI categories, except for underweight.

Furthermore, T2D is now increasingly found among the younger population $(3-5,25,31,32)$.
As expected, the study participants underestimated their weight in the overweight and obese categories. Underesti- mation of weight by girls is common across cultures, and the present findings are consistent with those of previous studies (7-12, 19, 33). Although females had significantly higher actual BMI than males, they underestimated their perceived weight. Awareness and knowledge of body weight were investigated by a study among Jamaican adults (19), and yielded similar findings with overweight and obese females underestimating their weight. Other studies of Jamaican children and adolescents, using actual height and weight, found that girls were more likely to be overweight and obese than boys (20-21, 23-24). However, perceptions of overweight and obesity were not assessed in those studies.

From the author's experience (SB), it is part of the Jamaican culture for adolescent girls to desire a large body frame. A large frame is considered to be more appealing to Jamaican males. However, the results of this study do not confirm this observation. Another study (33) indicated that "Jamaican adolescents are constantly bombarded with pictures of 
FIGURE 4. Comparison of perceived body mass index (BMI) by gender in a sample of 276 adolescents in Jamaica, 2007

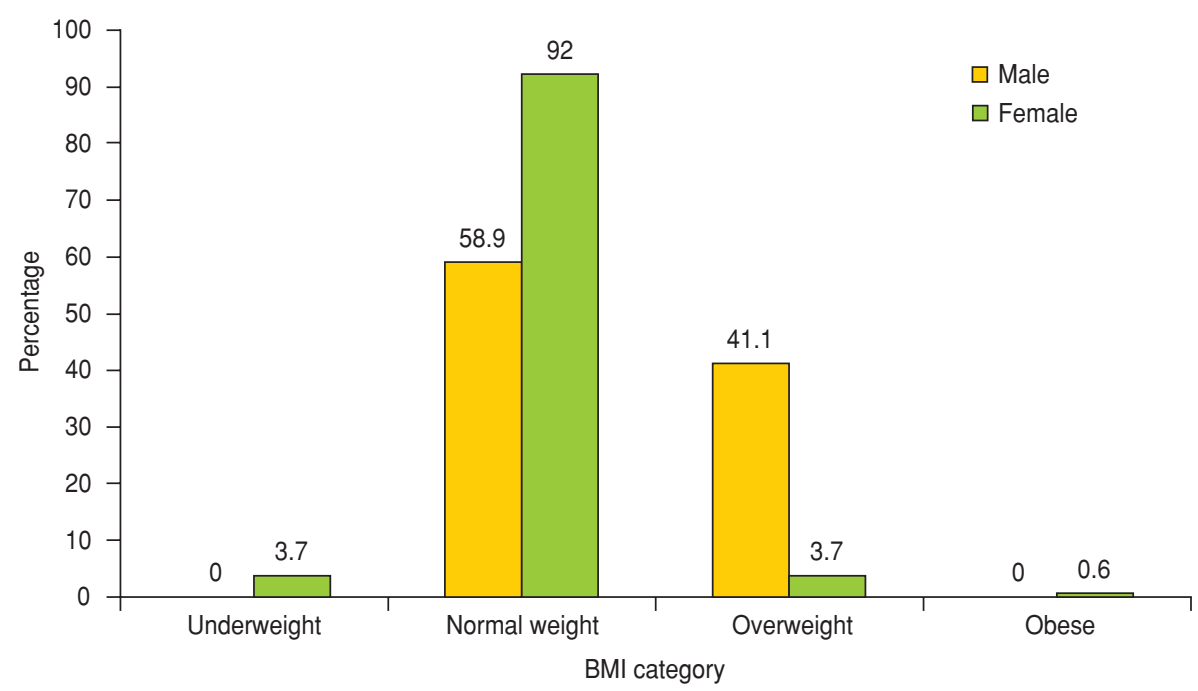

Note: Perceived BMI based on silhouettes, were classified using Cole and colleagues' $(28,29)$ classification of BMl for children 2-18 years of age based on age and sex. BMI from the silhouettes failed to classify male subjects as underweight for perceived BMI.

FIGURE 5. Comparison of desired body mass index (BMI) by gender, in a sample of 276 adolescents in Jamaica, 2007

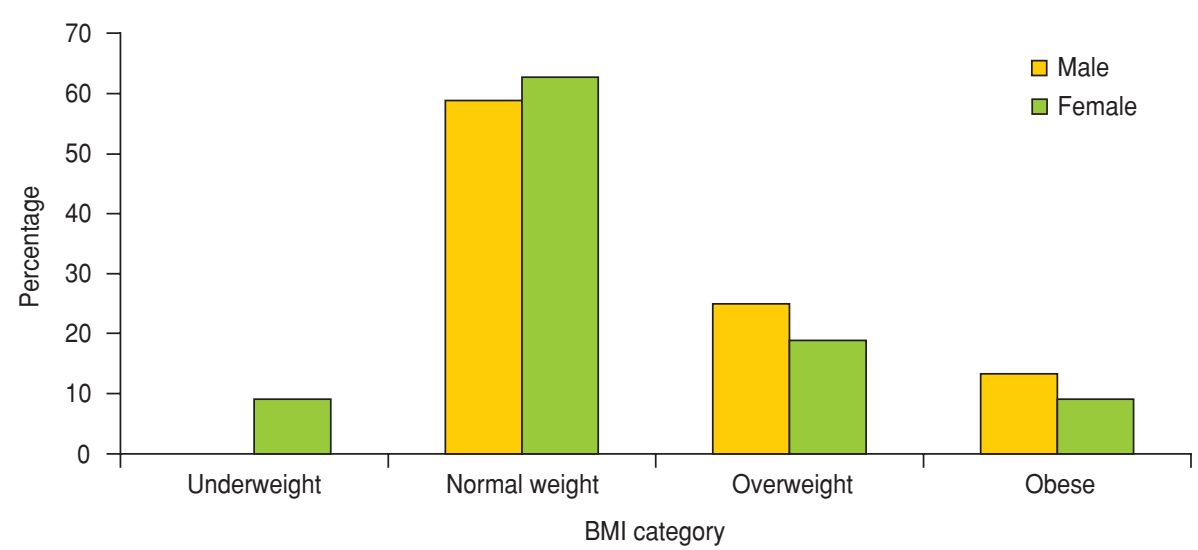

Note: Desired BMI based on silhouettes, were classified using Cole and colleagues' $(28,29)$ classification of BMI for children 2-18 years of age based on age and sex. The lowest BMI level on the silhouettes for male was 19.8. A BMI of $<18.5$ is required for underweight.

'curvy and plump' Jamaican dancers and performers ... [and] the lyrics of the local popular music suggest the attractiveness and desirability of heavier females" (33). In contrast to this observation of heavier females, the present study did not reveal desirability of large body frames. When compared to males within the same culture, females desired smaller body frames.

Females outnumbered males in all actual BMI categories, except for underweight. The study findings of underweight among Jamaican male adolescents were similar to those of a previous study (20). Other studies on Jamaican adolescents have consistently found a higher BMI in females than in males (18-24). Females outnumbered males in the present study (164 vs. 112). Females outnumber males in the upper grade levels in the Jamaican secondary schools because this is when students prepare for advanced level subjects, external examinations, and for entry into tertiary institutions, and typically, more females than males pursue higher education (34). Because the present study included subjects from 14-19 years of age, those 18-19 years of age from the upper grades were included, even though fewer males participated.

Males perceived and desired higher BMI than did females. However, females had significantly higher actual BMI than males. The higher actual BMI for females may be the result of earlier maturation. However, Tanner staging was not measured by this study; hence a relation between higher BMI and early maturation cannot be assumed. Blacks have consistently higher BMI than non-Blacks in studies in the United States $(25,32)$. In this sample, Blacks had slightly (not significantly) higher BMI than non-Blacks in both measured and perceived BMI. Jamaica's population is composed mostly of Blacks (91\%) (26). Therefore, it was difficult to get higher numbers of nonBlacks in the sample. Efforts to include a quota non-probability sample to include equal numbers of subjects from the different ethnic groups, would have affected randomization of the other variables in the study and the external validity of the results.

Higher BMI values were expected among urban adolescents, as found in studies with similar populations $(15,16$, 35). Higher BMI values among urban, as compared to rural, adolescents were associated with lower physical activity and consumption of more energy-dense foods (15-16). Others have found that in developing countries with low Gross Domestic Product (GDP), obesity tends to be higher in the urban areas than it is in rural ones (35). A similar pattern among urban adolescents was predicted for the present study. Still, others suggest that the prevalence of obesity tends to converge in most countries due to the spread of economic growth from the cities to the rural areas (36). Similarly, in industrial countries, the prevalence of obesity was greater in rural, than in urban areas (37). In the present study, urban adolescents had slightly higher mean BMI. Further studies are needed on rural and urban food intakes and physical activity patterns of adolescents to determine the causes of obesity.

The significance of this study lies in its ability to detect differences in perceived and desired versus actual BMI. As seen in other studies, girls are more likely to be overweight $(20,21,23,24,38)$ and to underestimate their weight (12-14). This can be a problem for implementing lifestyle changes, such as diet and physical activity, which help reduce weight and offset 
TABLE 4. Comparison of demographic characteristics of 276 adolescents and their actual, perceived, and desired body mass index (BMI), Jamaica, 2007

\begin{tabular}{|c|c|c|c|c|c|c|}
\hline \multirow{2}{*}{$\begin{array}{c}\text { Demographic } \\
\text { characteristics }\end{array}$} & \multicolumn{2}{|c|}{ Actual BMI } & \multicolumn{2}{|c|}{ Perceived BMI } & \multicolumn{2}{|c|}{ Desired BMI } \\
\hline & Mean (SDa) & $P$ value & Mean (SD) & $P$ value & Mean (SD) & $P$ value \\
\hline Gender & & $0.034^{b}$ & & $0.000^{c}$ & & $0.001^{c}$ \\
\hline Males & $22.8(6.8)$ & & $23.2(5.1)$ & & $23.3(1.9)$ & \\
\hline Females & $24.2(8.2)$ & & $22.8(4.5)$ & & $21.6(1.9)$ & \\
\hline Ethnicity & & 0.551 & & 0.178 & & 0.243 \\
\hline Blacks & $23.9(7.5)$ & & $23.1(4.8)$ & & $22.4(2.0)$ & \\
\hline Non-Blacks ${ }^{d}$ & $23.2(8.7)$ & & $22.3(4.8)$ & & $21.9(2.2)$ & \\
\hline Age (years) & & 0.406 & & 0.881 & & 0.695 \\
\hline $14-16$ & $23.6(7.4)$ & & $22.9(5.1)$ & & $22.3(2.1)$ & \\
\hline $17-19$ & $24.5(8.9)$ & & $23.2(3.7)$ & & $22.3(2.1)$ & \\
\hline Place of Residence & & 0.097 & & 0.127 & & 0.738 \\
\hline Rural & $22.9(7.6)$ & & $23.2(4.7)$ & & $22.1(2.1)$ & \\
\hline Urban & $24.5(7.8)$ & & $22.7(4.8)$ & & $22.5(2.1)$ & \\
\hline School-type & & 0.711 & & 0.441 & & 0.364 \\
\hline Traditionale & $23.94(8.8)$ & & $22.21(1.9)$ & & $22.93(5.1)$ & \\
\hline Non-traditional ${ }^{f}$ & $23.59(6.6)$ & & $22.40(2.2)$ & & $22.95(4.5)$ & \\
\hline $\begin{array}{l}\text { a Standard deviation. } \\
\text { b } P<0.05 \text {. } \\
\text { c } P<0.01 \text { level. } \\
\text { d Non-Blacks = Chines } \\
\text { e Educating students } 0 \\
\text { f Educating students } 0\end{array}$ & $\begin{array}{l}\text { of mixed ethni } \\
\text { ostly academic } \\
\text { cational training }\end{array}$ & & & & & \\
\hline
\end{tabular}

chronic diseases, such as T2D and CVD in later years (14). The obesity epidemic is associated with increasing rates of T2D in children and adolescents (39).

Adolescents desired both lower and higher BMI and had difficulty accepting their actual BMI. They may not be aware of the health risks associated with low or high BMI. There is strong evidence associating morbidity and mortality in adults who were overweight as adolescents. There are also health-risks associated with low BMI, such as infertility problems and delayed menarche among females. This study found a high percentage of underweight judging by actual measures of height and weight for age and gender. Overall, a higher percentage of males were classified as underweight using actual BMI measures.

Further research is needed on body size, body size perception, and risk of chronic nutrition-related diseases in this population. Overweight and obesity are among the indicators for the development of T2D and CVDs in later years. The current study suggests Jamaican adolescents had difficulty perceiving their actual BMI. They may be at risk for T2D and CVDs based on the high percentage of overweight and obesity found in this study sample. Furthermore, the subjects were unable to recognize themselves as being overweight or obese. Other conditions, such as high fasting plasma glucose, triglycerides, low-density lipopro- tein cholesterol, insulin resistance, glycated hemoglobin levels, dietary intakes, and low physical activity are risk factors for T2D and CVDs. These risk factors are associated with high BMI and need to be considered for future study.

Prevention programs are needed to offset chronic diseases associated with overweight. Programs should target all children and adolescents, and be culture- and gender-sensitive. Furthermore, children and adolescents need to be made aware of the health risks associated with overweight and obesity. Addressing the problem of overweight and obesity at an early age can be a primary prevention measure. Intervention programs are therefore necessary and can be carried out in the school setting. Moreover, secondary school attendance is mandatory in Jamaica and it is likely that health screenings of this nature would reach a wide cross-section of the adolescent population. Interventions may include increasing physical activity, and changes to the dietary habits of adolescents in order to decrease the prevalence of obesity and related chronic diseases in later life.

\section{Limitations}

This study had several limitations. First, the scale used to determine perceived and desired BMI was developed for the adult Caucasian population.
Therefore, the body images may not be representative of Black, Jamaican adolescents. The researchers did not find a figural representation of body images for adolescents for this study. In Jamaica, it is culturally acceptable to have a large body frame, therefore subjects might not have associated the large body frames of some of the silhouettes as being overweight or obese.

Traditional versus non-traditional schools were considered as a surrogate measure of SES. As such, students attending non-traditional schools were assumed to have lower SES and higher mean BMI than those attending traditional schools. The lack of association between SES and BMI could not be explained by type of school.

The presence of nine outliers (BMI > $40)$, contributed to higher actual BMI, as well as greater standard deviations when compared to other studies among Jamaican adolescents $(23,24)$. Actual BMI ranged from 12.9-50.8 in this study. Due to the small sample size of this study, these outliers were not removed. The sample size was small compared to other similar studies $(23,24)$, and included subjects from five of the 14 parishes. A wider cross-section of adolescents is needed to adequately represent the prevalence of overweight and obesity among adolescents in Jamaica. No other measure of adiposity was used and all comparisons were made using BMI as the only mea- 
sure of overweight. Subjects' high BMI might have included lean muscle mass and not necessarily excess body fat.

The study used the suggested international cut-off points for overweight and obesity for 2-18 year olds based on age and gender (27). These reference standards might not be the best for the sample used. Other limitations of the international standard for grading overweight and obesity of adolescents are that it does not differentiate among ethnic groups. Earlier research indicated that lower BMI cut-off points for overweight are needed for Asians compared to Caucasians (40); the same may be true for Jamaican adolescents.

\section{Conclusions}

The study compared Jamaican adolescents' perceptions of their BMI with their actual BMI. Adolescents underestimated their weights for actual and perceived BMI in all categories; underweight, normal weight, overweight-and obese. Therefore, the inability of adolescents to see themselves as overweight or obese may be a major obstacle to promoting lifestyle changes in this age group. Actual, perceived, and desired mean BMI were significantly different by gender. Females had significantly higher actual BMI than males, whereas males perceived and desired higher BMI than females. There were no significant differences in mean BMI for the actual, perceived, and desired BMI based on ethnicity, age, SES, and place of residence.

The results from this study suggest that interventions are needed to achieve the following: improve knowledge of a healthy body weight while preserving self-esteem; increase understanding of the relationship of body weight to chronic diseases; access to and knowledge of healthy dietary and physical activity choices; and finally, perceived susceptibility to health risks associated with lifestyles.

Acknowledgements. The authors acknowledge the support of the Heart Foundation of Jamaica; the Diabetes Association of Jamaica; the Central Medical Laboratory, Kingston; the Jamaican Ministry of Health and Environmental Control; and the Ministry of Education and Youth, for accommodating the data collection. The authors would like to thank the Foundation of Dietetics and Nutrition, and the University's Graduate School Dissertation Year Fellowship, Florida International University, for funding this research.

\section{REFERENCES}

1. Ogden CL, Carroll MD, Flegal KM. High body mass index for age among U.S. children and adolescents, 2003-2006. J Am Med Assoc. 2008;299:2401-5.

2. Kumanyika S, Jeffrey RW, Morabia A, Ritenbaugh C, Antipatis VJ. Obesity prevention: the case for action. Int J Obes Relat Metal Disord. 2002;26:425-36.

3. Daniels SR. The consequences of childhood overweight and obesity. The future of children. 2006;16(1):47-67.

4. Choudbury P. Adolescent onset of adult metabolic diseases. J Indian Med Assoc. 2005; 103(11):630-7.

5. Reinehr T. Clinical Presentation of type 2 diabetes mellitus in children and adolescents. Int J Obes. 2005;(suppl 2):S105-10.

6. Kindes M. Body image: new research. Nova Science Publishers Inc.: New York; 2006. Pp. 215.

7. Wadden TA, Foster GD, Stunkard AJ, Linowitz JR. Dissatisfaction with weight and figure in obese girls: discontent but not depression. Int J Obes. 1989;3(1):89-97.

8. Desmond SM, Price JH, Gray N, O'Connell JK. The etiology of adolescents' perceptions of their weight. J Youth Adoles. 1986;15:461-74.

9. Swallen K, Reither E, Haas S, Meier A. Overweight, obesity and health related quality of life among adolescents. The National Longitudinal Study of Adolescent Heath. Pediatrics. 2005; 115(2):340-7.

10. Hesketh K, Wake M, Waters E. Body mass index and parent-reported self-esteem in elementary school children. Evidence for a causal relationship. Int J Obes. 2004;28:1233-7.

11. Brener ND, Eaton DK, Lowry R, McManus T. The association between weight perception and BMI among high school students. Obes Res. 2004;12:1866-74.
12. Elgar FJ, Roberts C, Tudor-Smith C, Moore L. Validity of self-reported height and weight and predictors of bias in adolescents. J Adoles Health. 2005;37:371-5.

13. Wang Y, Monteiro C, Popkin BM. Trends of obesity an underweight in older children and adolescents in the United States, Brazil, China and Russia. Am J Clin Nutr. 2002;(75): 97-107.

14. Skinner AC, Weinberger M, Mulvaney S, Schlundt D, Rothman RL. Accuracy of perceptions of overweight and relation to selfcare behaviors among adolescents with type 2 diabetes and their parents. Diabetes Care. 2008;31:227-9.

15. Prentice A. The emerging epidemic of obesity in developing countries. Int J Epidemiol. 2006; 35:93-9.

16. Popkin BM. Urbanization, lifestyle changes and the nutrition transition. World Development. 1999;27:1905-16.

17. Caribbean unity to stop chronic disease epidemic-obesity a major target. The Jamaica Gleaner. Available from: www.jamaica gleaner.com/gleaner/20070829/carib/carib4. html. Accessed on 23 September 2009.

18. Pan American Health Organization. PAHO representative highlights chilling effects of noncommunicable diseases. Jamaica Information Service; 2008. Available from: http:// www.jis.gov.jm. Accessed on 1 February 2009.

19. Ichinohe M, Mita R, Saito K, Shinka H, Nakaji $\mathrm{S}$, Coombs M, et al. The prevalence of obesity and its relationship with lifestyle factors in Jamaica. Tohoku J Exp Med. 2005;207:21-32.

20. Jackson M, Samms-Vaughan M, Ashley D. Nutritional status of 11-12 year-old Jamaican children: coexistence of under- and overnutrition in early adolescence. Pub Health Nutr. 2002;5(2):281-6.
21. Gaskin PS, Walker SP. Obesity in a cohort of black Jamaican children as estimated by BMI and other indices of adiposity. Eur J Clin Nutr. 2003;57(3):420-6.

22. Ragoobirsingh D, Morrison EYSt. A. , Johnson P, Lewis-Fuller E. Obesity in the Caribbean: the Jamaican experience. Diabetes Obes Met. 2004;6:23-7.

23. Ferguson TS, Tulloch-Reid MK, Younger NOM, Knight-Madden JM, Samms-Vaughn $\mathrm{M}$, Ashley D, et al. Prevalence of the metabolic syndrome and its components in relation to socioeconomic status among Jamaican young adults: a cross-sectional study. BMC Pub Health. 2010;10. DOI: 10.1186/1471-2458-10-307.

24. Francis DK, Van Broeck J, Younger N, McFarlane S, Rudder K, Gordon-Strachan G, et al. Fast-food and sweetened beverage consumption: association with overweight and high waist circumference in adolescents. Pub Heath Nutr. 2009;12(8):1106-14.

25. Berry D, Sheehan R, Heschel R, Knafl K, Melkus G, Grey M. Family based interventions for childhood obesity: A review. J Fam Nurs. 2004;10:429-49.

26. Jamaica facts and figures, 2005. Available from: http://encarta.msn.com/fact_631504789/ Jamaica_Facts_and Figures.html. Accessed on 28 June 2006.

27. Cole TJ, Bellizzi MC, Flegal KM, Dietz WH. Establishing a standard definition for child overweight and obesity worldwide: international survey. Br Med J. 2000;320:1240-3.

28. Cole T, Flegal KM, Nicholls D, Jackson AA. Body mass index cut offs to define thinness in children and adolescents: International survey. Br Med J. 2007;335(7612):194-201.

29. Bulik CM, Wade TD, Heath AC, Martin NG, Stunkard AJ, Eaves LJ. Relating body mass index to figural stimuli: population-based 
normative data for Caucasians. Int $\mathrm{J}$ Obes Relat Metal Disord. 2001;25(10):1517-24.

30. Epstein FH, Higgins M. Epidemiology of obesity. In: Obesity. Bjorntorp P, Brodoff BN, eds. Philadelphia: JB Lippincott; 1992. Pp. 330-42.

31. American Diabetes Association. Clinical practice recommendations. Diabetes Care. 2005;28 (suppl 1):1-79.

32. McKnight-Menci H, Sababu S, Kelly SD. The care of children and adolescents with type 2 diabetes. J Pedia Nurs. 2005;20(2):96-106.

33. Smith DE, Cogswell C. A cross-cultural perspective on adolescent girls' body perception. Perceptual Motor Skills. 1994;78:744-6.

34. Miller E. Marginalization of the Jamaican male. Mona, Jamaica: Institute of Social and
Economic Studies, University of the West Indies; 1986.

35. Peytremann-Bridevaux I, Faeh D, SantosEggimann B. Prevalence of obesity on rural and urban settings of 10 European countries. Prev Med. 2007;44:442-6.

36. Mendez MA, Monteiro CA, Popkin BM. Overweight exceeds underweight among women in most developing countries. Am J Clin Nutr. 2005;81:714-21.

37. Boehm BO, Claudi-Boehm S, Yildirim S, Haenle MM, Hay B, Mason RA, et al. The Romerstein Group: the Emil-Study Group, 2005. Prevalence of the metabolic syndrome in southwest Germany. Scand J Clin Lab Investig. 2005;(suppl 240):122-8.
38. Borders TF, Rohrer JE, Cardarelli KM. Gender specific disparities in obesity. J Community Health. 2006;31:57-68.

39. Rosenbloom AL, Joe JR, Young RS, Winner WE. Emerging epidemic of type 2 diabetes in youth. Diabetes Care. 1999;22:345-54.

40. Deurenberg P, Deurenberry-Yap M, Guricci S Asians are different from Caucasians and from each other in their body mass index/ body fat percent relationship. Obes Rev. 2002; 3:141-6.

Manuscript received on 9 June 2010. Revised version accepted for publication on 3 February 2011.

RESUMEN Objetivo. Comparar el tamaño corporal autopercibido, el tamaño corporal deseado y el índice de masa corporal real (IMC) en adolescentes de Jamaica y analizar las implicaciones de dichas percepciones en la prevención de las enfermedades crónicas.

Comparación del peso autopercibido y el peso Métodos. El estudio se realizó en octubre del 2007 y participaron 276 adolescentes jamaiquinos de 14 a 19 años de edad, seleccionados aleatoriamente entre los grados 9 y 12 de 10 escuelas secundarias. Se midió el IMC percibido y el deseado usando figuras con una silueta corporal que representaban nueve categorías del IMC para hombres y mujeres, y se compararon con el IMC real de los participantes. masa corporal real en adolescentes de Jamaica

Resultados. La media de la edad fue de 15,6 $\pm 1,2$ años. De acuerdo con los valores reales del IMC, $24,6 \%$ de los participantes se clasificaron como con peso inferior al normal; $39.9 \%$, como normales; $14,5 \%$, como con sobrepeso; y $21 \%$, como obesos. Hubo diferencias significativas entre el IMC real y el percibido $(P<0,01)$, entre el IMC real y el deseado $(P<0,01)$ y entre el IMC percibido y el deseado $(P<0,01)$. El sexo constituyó una diferencia significativa para el IMC real $(P<0,05)$, percibido y deseado $(P<0,01)$. Las mujeres tenían un IMC real medio significativamente mayor que los hombres $(P<0,05)$. Los adolescentes varones se autopercibían como con un IMC mayor y un IMC deseado mayor que las mujeres. No hubo diferencias en cuanto al grupo étnico, la edad, el lugar de residencia y la situación socioeconómica en el IMC real, percibido y deseado en esta población de estudio $(P>0,05)$.

Conclusiones. Las mujeres tenían un IMC real mayor y un IMC percibido menor que los hombres. Los adolescentes jamaiquinos tenían un IMC similar, independientemente de su grupo étnico, edad, lugar de residencia o situación socioeconómica. Es necesario realizar intervenciones para mejorar los conocimientos sobre el peso corporal saludable y sobre la relación entre el peso corporal, las opciones de modos de vida y las implicaciones del peso corporal excesivo en las enfermedades crónicas.

Palabras clave Salud del adolescente; nutrición del adolescente; composición corporal; índice de masa corporal; sobrepeso; obesidad; Jamaica. 